\title{
Studies on selected molecular factors in endometrial cancers
}

\author{
Anna Markowska ${ }^{1, A, D, F}$, Monika Szarszewska ${ }^{2, A-C}$, Jakub Żurawskij ${ }^{3, B, C}$, Stefan Sajdak ${ }^{4, B}$, Paweł Knapp ${ }^{5, B}$, Anna Grybos s., $^{6}$, \\ Anita Olejek, ${ }^{7, B}$, Wiesława Bednarek ${ }^{8, B}$, Andrzej Roszak ${ }^{9, B}$, Marcin Jóźwik ${ }^{10, B}$, Andrzej Marszałek ${ }^{11, B, C}$, Violetta Filas ${ }^{11, B, C}$, \\ Katarzyna Wójcik-Krowiranda ${ }^{12, B}$, Radosław Mądry 2,B, Janina Markowska ${ }^{2, A, E, F}$, Rafał Sozański 13,B \\ 1 Department of Perinatology and Gynecology, Poznan University of Medical Sciences, Poland \\ 2 Department of Gynecological Oncology, Poznan University of Medical Sciences, Poland \\ ${ }^{3}$ Department of Biology and Environmental Protections, Division of Immunobiochemistry, Poznan University of Medical Sciences, Poland \\ ${ }^{4}$ Department of Gynecological Surgery, Poznan University of Medical Sciences, Poland \\ ${ }^{5}$ Department of Gynecology and Gynecologic Oncology, Medical University of Bialystok, Poland \\ ${ }^{6}$ Department of Gynecology and Obstetrics, Faculty of Health Science, Wroclaw Medical University, Poland \\ ${ }^{7}$ Department of Gynecology, Obstetrics and Oncologic Gynecology, Medical University of Silesia, Bytom, Poland \\ ${ }^{8}$ Chair and Clinic of Gynecological Oncology, Medical University of Lublin, Poland \\ ${ }^{9}$ Department of Electroradiology, Poznan University of Medical Science, Greater Poland Cancer Centre, Poland \\ ${ }^{10}$ Chair and Department of Gynecology, Gynecologic Endocrinology and Obstetrics, University of Warmia and Mazury in Olsztyn, Poland \\ ${ }^{11}$ Department of Tumor Pathology and Prophylaxis, Poznan University of Medical Sciences, Greater Poland Cancer Center, Poland \\ ${ }^{12}$ Department of Gynecological Oncology, Medical University of Lodz, Poland \\ ${ }^{13}$ st $^{\text {st }}$ Department and Clinic of Gynaecology and Obstetrics, Wroclaw Medical University, Poland \\ A - research concept and design; $B$ - collection and/or assembly of data; $C$ - data analysis and interpretation; \\ $D$ - writing the article; $E$ - critical revision of the article; $F$ - final approval of the article
}

Address for correspondence

Monika Szarszewska

E-mail: monika.szarszewska@gmail.com

Funding sources

None declared

Conflict of interest

None declared

Received on January 28, 2017

Reviewed on April 10, 2017

Accepted on May 2, 2017

DOI

10.17219/acem/70861

Copyright

Copyright by Author(s)

This is an article distributed under the terms of the

Creative Commons Attribution Non-Commercial License

(http://creativecommons.org/licenses/by-nc-nd/4.0/)

\section{Abstract}

Background. Endometrial carcinomas (EC) differ in etiology, clinical course and prognosis.

Objectives. This multi-center study aimed at a closer recognition of molecular factors linked to heterogeneity of EC by evaluating estrogen and progesterone receptors, proteins dependent on MMR genes, proteins linked to poor prognosis and metastases, and mutations in BRCA1.

Material and methods. Using sections of paraffin-embedded preparations, in 115 patients with EC type I and 31 with EC type II, expression of ERa, ERß1, PR, MLH1, and MSH2 proteins, as well as ARID1A, c-MET and BRCA1, was estimated by immunohistochemistry using specific antibodies.

Results. Expression of ERß1 was augmented in EC type II, in poorly differentiated cancers and with growing clinical advancement. An augmented expression of ERa was noted in well-differentiated EC and at lower clinical stage. An increased expression of PR and decreased of MLH1 were detected in type I EC. The expression of ARID1A and c-MET proteins showed no differences between the types of EC, stages of clinical advancement or grading. In 51.6\% patients with type II EC, a loss of BRCA1 expression was disclosed; in this group of cancers a decreased expression of ERa was noted.

Conclusions. An augmented expression of ERß1 was linked to type II EC. A higher expression of ERa in EC cancers was associated with a lower histopathological grade. A decreased expression of MLH1 protein was estimated in EC type I. Type II EC may be connected to BRCA1 mutation.

Key words: endometrial cancer, BRCA1, estrogen receptors, MMR, ARID1A 


\section{Introduction}

According to global statistics, endometrial carcinoma (EC) is diagnosed in $4.8 \%$ of the female population. In 2012, EC developed in 319,605 women, of which 76,160 cases were fatal. In Europe since 2005 a stable increase has been noted in morbidity and mortality due to EC. In 2012 almost 100,000 women developed EC, which accounts for $6.2 \%$ of all morbidities due to malignant tumors in women. ${ }^{1,2}$

Multi-year observations indicate that ECs vary in etiology, clinical course and prognosis. Since Bokhman's hypothesis was $1^{\text {st }}$ proposed, 2 types of EC have been distinguished. ${ }^{3}$

Type I is the most frequently diagnosed in around $80 \%$ women: mainly endometrioid, it is linked to an unbalanced estrogen stimulation and metabolic syndrome, manifests a slow course and good prognosis. It carries common receptors for estrogens (ER) and progesterone (P), while their expression depends on the degree of clinical advancement and histological grade. Most of the cancers are sporadic; around $3-5 \%$ are linked to mutations in the mismatch repair genes (MMR): MLH1, MSH2, MSH6 and PMS2. In this type of EC, molecular tests demonstrated mutations in PTEN, PIK3CA, K-RAS and $\beta$-catenin, as well as microsatellite instability (MSI). ${ }^{4-9}$

Type II is a non-endometrioid cancer that manifests an aggressive biology, encompassing serous, clear-cell and poorly differentiated cancers. Frequent relapses cause an unfavorable course. It is a carrier of TP53 (p53) and HER2/neu mutations. A proportion of the cancers was demonstrated to carry ER hormonal receptors, the effect of which on the clinical course remains controversial. ${ }^{10-15}$

Uterine serous carcinoma (USC) is thought to represent a unique type of EC, which should be treated as a distinct morbid unit. ${ }^{16}$

The results of studies covered by the Human Cancer Genetic Program (543 unselected female endometrial cancers) and focused on MSI demonstrated that, even though MSI was documented in $21.7 \%$ of the studied cases, genetic testing for MMR (MLH1, MSH2, MSH6 and PMS2) detected Lynch syndrome in just $1.8 \%$ of cases. ${ }^{17}$ Another study showed that MSI was more frequent in metastatic than in primary EC, that it appeared late in tumor development and that it might promote progression. ${ }^{18}$ Brinton et al., when reporting the results of the Gynecologic Oncology Group (GOG 210 Trial), highlighted the similarity of endometrioid grading 3 (G3) cancers and type II cancers. ${ }^{19}$ The authors supported the hypothesis suggesting heterogeneity of EC type II cancers.

As stated above, the mutation of PIK3CA is linked to EC type I, although alterations in $P I K 3 C A$ are also present in USC. ${ }^{20}$ Studies by Takeda et al. showed that mutations in the ARID1A suppressor gene induce an altered expression of many genes, including $M L H 1$ and genes linked to the PI3K/AKT signaling pathway, and are therefore associated with both type I and type II EC. ${ }^{21}$ The PI3K signaling pathway also involves the $M E T$ proto-oncogene and its HGF ligand. Studies by Bishop et al. proved that the expression of c-MET occurred likewise in USC. ${ }^{22}$

In recent years USC has been found to be potentially associated with carriership of a mutated BRCA1 gene. Bruchim et al. subjected women with histologically documented USC to genotyping of 3 main mutations, including BRCA1 (185delAG and 5382insc) and BRCA2 (6174delT). ${ }^{23}$ They found that over $25 \%$ of women with USC carried mutations in BRCA1/2. Similar observations were made in English women in 2013; 68\% of patients with USC had suffered from breast cancer before being diagnosed with USC. The authors also proposed that at least a subgroup of USC should be recognized as hereditary breast/ovarian cancer, which might carry prophylactic implications (prophylactic adnexectomy) and therapeutic implications (inhibitors of poly adenosine diphosphate ribose polymerase - PARP). ${ }^{24}$ The heterogeneity of EC, particular of EC type II, requires further molecular studies.

This study aimed to estimate expression manifested by hormonal receptors (ER $\alpha, \mathrm{EB} \beta 1, \mathrm{PR}$ ), expression of $\mathrm{MSH} 2$ and MLH1 proteins involved in the development of certain endometrial cancers belonging to the Lynch syndrome, expression of proteins linked to poor prognosis and metastases (ARID1A, c-MET), and expression of BRCA1 protein in type II EC, which might indicate that a proportion of the cancers are dependent on mutations in BRCA1 and represents a proportion of breast/ovarian cancer syndrome.

\section{Material and methods}

The study had a multi-center, retrospective character. The research material included archival histopathological preparations of endometrial carcinoma, obtained from 162 patients diagnosed and treated due to EC in 2007-2014 in 8 specialized centers treating the diseases from the oncological gynecology branch. The study group consisted of patients treated primary with surgery. Due to insufficient clinical data in 16 patients, further analyses were conducted on 146 patients. The mean age of the patients was 65.1 years.

In the studied group, EC of endometrioid type was diagnosed in 115 patients (78.8\%); 31 patients (21.2\%) were diagnosed with EC of non-endometrioid type, including 18 patients with serous cancer $(12.3 \%) ; 11$ patients with clear-cell cancer (7.5\%) and 2 patients with mucinous cancer (1.4\%).

Seventy-four patients (50.7\%) were diagnosed at an early stage of clinical advancement (38 patients manifesting grade IA and 36 patients manifesting grade IB; $26 \%$ and $24.7 \%$, respectively). Thirty-seven patients $(25.4 \%)$ were diagnosed at stage II, 22 patients (15\%) at stage III and 13 patients $(8.9 \%)$ at stage IV, according to International Federation of Gynecology and Obstetrics (FIGO) gynecologic cancer staging system. In 38 patients (25\%) endometrial 
carcinoma demonstrated a high grade of histological differentiation (G1), 59 patients (38.8\%) had an intermediate grade (G2), while 55 patients $(36.2 \%)$ carried a poorly differentiated tumor (G3) (Table 1).

Tissue material in the form of neoplastic endometrium was fixed in $10 \%$ buffered formalin, passed according to classical histopathological techniques and embedded in paraffin blocks. Following the evaluation of hematoxylin and eosin-stained (HE-stained) preparations and diagnosis, further studies were conducted on representative preparations. In order to demonstrate the presence of antigens in the tissue material, antibodies were employed specific for: ARID1A (Novus Biological, Littleton, USA NBP1-88932), ER $\alpha$ (Santa Cruz Biotechnology, Santa Cruz, USA sc-8005, clone D-12), ERß1 (Zytomed Systems, Berlin, Germany MSK042-05, clone PPG5/10), Met (Santa Cruz Biotechnology, Santa Cruz, USA sc-10, clone C-12), MLH1 (Leica NCL-L, Buffalo Grove, USA NCL-L-MLH1, clone ES05), MSH2 (Invitrogen, Carlsbad, USA 33-7900, clone FE11), PgR (Dako, Santa Clara, USA M3569, clone 636), BRCA1 (Abcam, Cambridge, UK ab16780, clone MS110).

The preparations were incubated in a water bath at $96^{\circ} \mathrm{C}$ in a citrate buffer, $\mathrm{pH}$ 6.0, for $50 \mathrm{~min}$. The activity of endogenous peroxidase was blocked using $3 \% \mathrm{H}_{2} \mathrm{O}_{2}$. The preparations were incubated with the antibody at room temperature for $60 \mathrm{~min}$, followed by $10 \mathrm{~min}$ rinsing in tris-buffered saline (TBS). The tissue material was incubated with the EnVision system (DakoCytomation, K5007; Dako, Santa Clara, USA) for $30 \mathrm{~min}$. In all preparations, 3,3'-diaminobenzidine (DAB-3.3) was used to visualize the reaction. Subsequently, the preparations were counterstained with Mayer's hematoxylin, then passed through a row of alcohol to xylene and finally closed under a coverslip.

In immunohistochemical tests the negative control involved a reaction with omission of the primary antibody. Using an Olympus BX 43 light microscope and XC 30 digital camera (Olympus, Shinjuku, Tokyo, Japan), 10 photographs were taken of every stained preparation with the immunohistochemical reaction. The photographs were taken at total magnification of $\times 400$.

In the evaluation of staining intensity reflecting expression of ARID 1A, ER $\alpha, E R \beta 1$, Met, MLH1, MSH2 and PR proteins, a 4-degree scale was applied:

- 0 - absence of reaction;

- + - reaction obtained in 1-50 immunopositive cells (cell nuclei or cytoplasm);

- ++ - reaction obtained in 50-75 immunopositive cells;

- +++ - reaction obtained in 75-100 immunopositive cells, in every instance seen in 10 visual fields.

Staining intensity ++ and +++ were considered in further analyses as a positive protein expression.

The expression of BRCA1 protein was evaluated in cancer tissue in patients with non-endometrioid cancer. In the cases where the BRCA1/MLH1/MSH2 expression were evaluated in the studied preparations, it was assumed that the presence of the color reaction indicated an absence
Table 1. Characteristics of patients included in the study

\begin{tabular}{|c|c|c|}
\hline FIGO stage & Grading & Number of patients \\
\hline \multicolumn{3}{|c|}{ Endometrioid adenocarcinoma $(n=115)$} \\
\hline \multirow{3}{*}{$\mid \mathrm{A}$} & G1 & 14 \\
\hline & G2 & 15 \\
\hline & G3 & 4 \\
\hline \multirow{3}{*}{ IB } & G1 & 9 \\
\hline & G2 & 15 \\
\hline & G3 & 8 \\
\hline \multirow{3}{*}{$\|$} & G1 & 10 \\
\hline & G2 & 11 \\
\hline & G3 & 6 \\
\hline \multirow{2}{*}{$\| \mathrm{A}$} & G2 & 6 \\
\hline & G3 & 2 \\
\hline IIIB & G2 & 2 \\
\hline \multirow{2}{*}{$\| I I C 1$} & G1 & 2 \\
\hline & G2 & 2 \\
\hline IVA & G2 & 1 \\
\hline \multirow{3}{*}{ IVB } & G1 & 1 \\
\hline & G2 & 4 \\
\hline & G3 & 3 \\
\hline \multicolumn{3}{|c|}{ Serous adenocarcinoma $(n=18)$} \\
\hline IA & G3 & 4 \\
\hline $\mathrm{IB}$ & G3 & 3 \\
\hline$\|$ & G3 & 7 \\
\hline $\mathrm{IIIC1}$ & G3 & 4 \\
\hline \multicolumn{3}{|c|}{ Clear cell adenocarcinoma $(n=11)$} \\
\hline $\mathrm{IA}$ & G3 & 1 \\
\hline $\mathrm{IB}$ & G3 & 1 \\
\hline$\|$ & G3 & 2 \\
\hline IIIA & G3 & 1 \\
\hline$\| I I C 1$ & G3 & 3 \\
\hline IVA & G3 & 2 \\
\hline IVB & G3 & 1 \\
\hline \multicolumn{3}{|c|}{ Mucinous adenocarcinoma $(n=2)$} \\
\hline$\|$ & G1 & 1 \\
\hline IVB & G2 & 1 \\
\hline
\end{tabular}

FIGO - International Federation of Gynecology and Obstetrics; G1 - endometrial carcinoma demonstrating a high grade of histological differentiation; G2 - endometrial carcinoma demonstrating an intermediate grade of histological differentiation; G3 - poorly differentiated endometrial carcinoma.

of mutations in the BRCA1/MLH1/MSH2 gene while the absence of a color reaction indicated the loss of protein expression, which may be the result of the BRCA1 gene mutation and $M L H 1 / M S H 2$ mutations or hypermethylation of their promoter in the cancer tissue. The immunohistochemical reaction was detected in both cell nuclei and in the cytoplasm with the use of the ER $\beta 1$-specific antibody. 

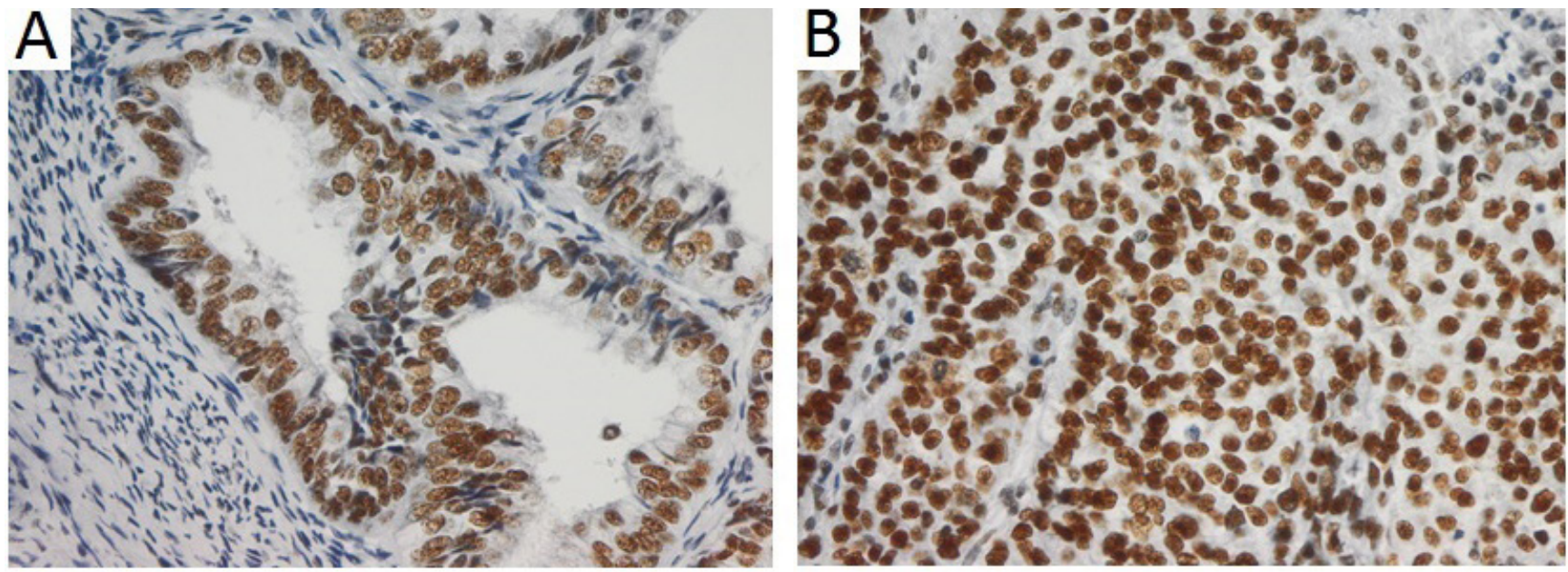

Fig. 1. Nuclear expression of ARID1A: A) in cell lining glands of highly mature adenocarcinoma (immunohistochemical reaction ++ ); B) in solid tissue (with pronounced reaction +++ ). Magnification $\times 400$
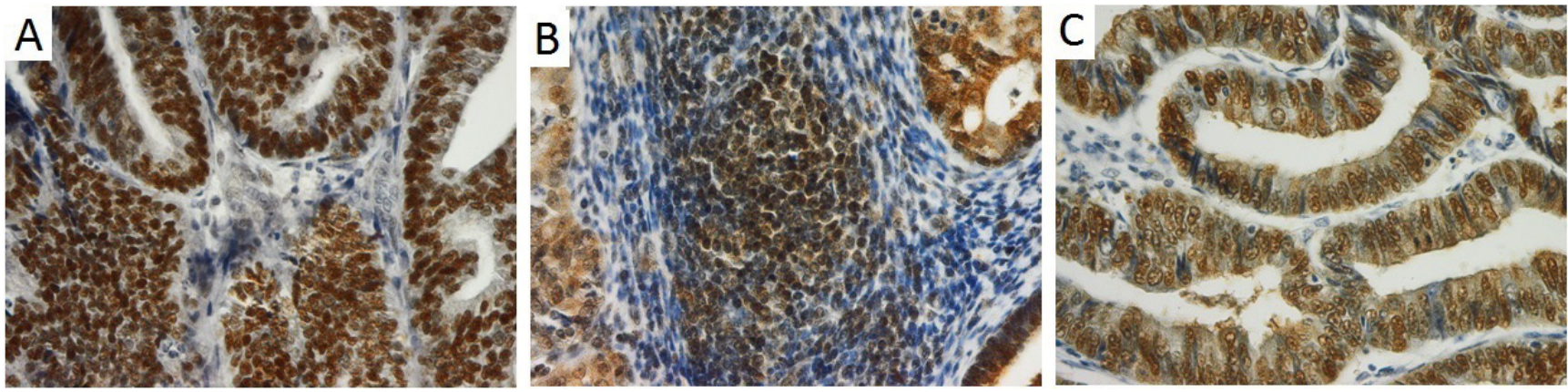

Fig. 2. Nuclear expression of: A) ERa receptor; B) ERß1 receptor; C) PR receptor in endometrial adenocarcinoma. Magnification $\times 400$

The c-MET protein manifested a cytoplasmic reaction while a nuclear reaction was shown by reactions detecting MLH1, MSH2, BRCA1, PR, ER $\alpha$ and ARID1A (Fig. 1-5).

Statistical calculations were performed with STATISTICA v. 10 software (StatSoft Inc., Tulsa, USA). The MannWhitney, the Kruskal-Wallis and Spearman's tests were used. Statistical significance was set at $\mathrm{p}<0.05$.

\section{Results}

\section{Histological type}

Based on histopathological diagnosis, the patients were divided into 2 groups: patients with 1) endometrioid type and 2) non-endometrioid type of cancer. The latter group included patients with serous cancer, clear-cell cancer and mucinous cancer. In patients with endometrioid type cancer, a decreased expression of both MLH1 protein and $E R \beta 1$ was observed $(p=0.013$ and $p=0.035$, respectively) (Fig. 6). A reduced expression of PR receptor was detected (intensity of the reaction of 3-2 vs 1-0) among patients with non-endometrioid EC ( $\mathrm{p}=0.041)$. The reduced immunohistochemical expression of PR receptor was seen mainly in patients with serous cancer $(\mathrm{p}=0.022)$, while intensified immunohistochemical reactions for MLH1 and ER $\beta 1$ involved clear-cell cancers $(p=0.02184$ and $p=0.00109$ ). Following the subdivision of non-endometrial cancers to individual subtypes, the subgroup of patients with clear-cell cancers manifested a reduced expression in the immunohistochemical reaction specific for ER $\alpha$ receptors as compared to the expression noted in endometrioid cancers $(\mathrm{p}=0.048)$ and a higher expression of immunohistochemical reaction for ER $\beta 1$ as compared to expression noted in serous cancers $(\mathrm{p}=0.02658)$. No differences were detected in the expression of immunohistochemical reactions specific for the remaining proteins in the studied groups.

\section{Grading}

An increase in the expression of ER $\beta 1$ receptor was found in parallel to the decrease in histopathological differentiation (G3 vs G1 p = 0.003) (Fig. 7). Patients with G1 or G2 endometrial cancer manifested a higher expression of $E R \alpha$ receptors than patients with a G3 cancer (G1 + G2 vs G3) $(\mathrm{p}=0.011)$. No differences were detected in the expression of MLH1, MSH2, PR, c-MET and ARID1A dependent on the histopathological grading of the cells. 

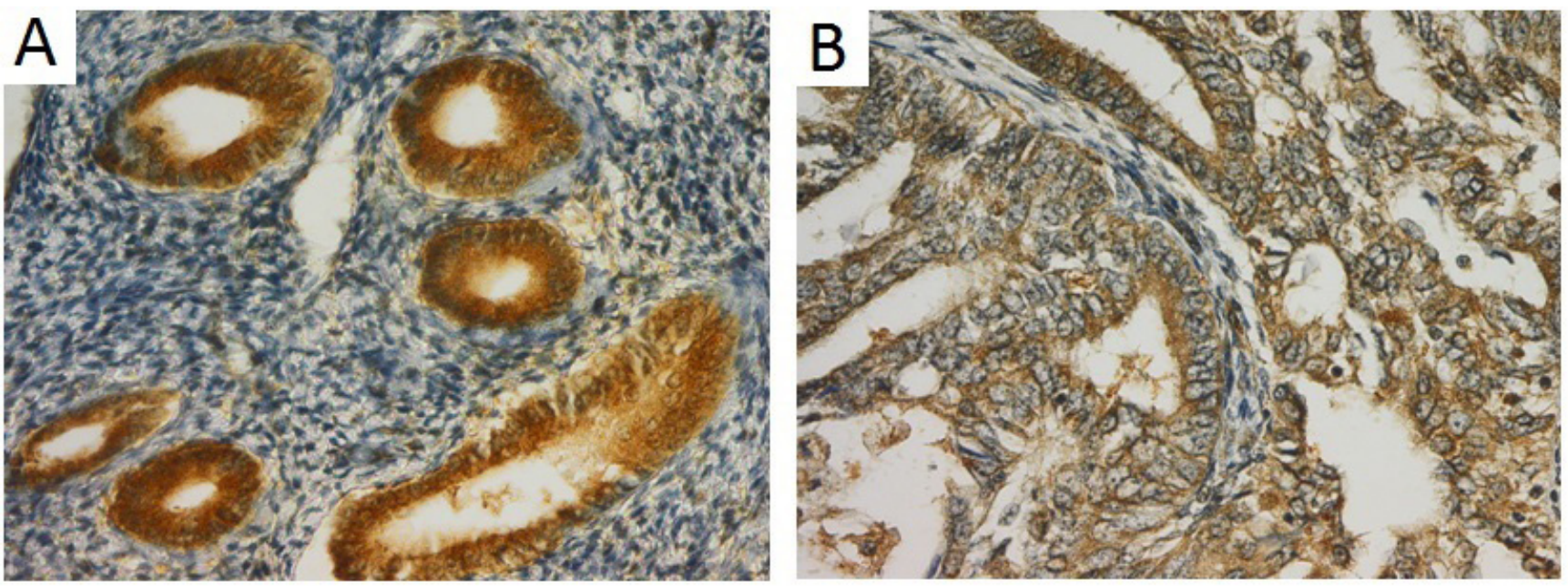

Fig. 3. A pronounced cytoplasmic reaction with c-MET-specific antibody in a section of endometrial adenocarcinoma (A and B). No such reaction in cell nuclei. Magnification $\times 400$
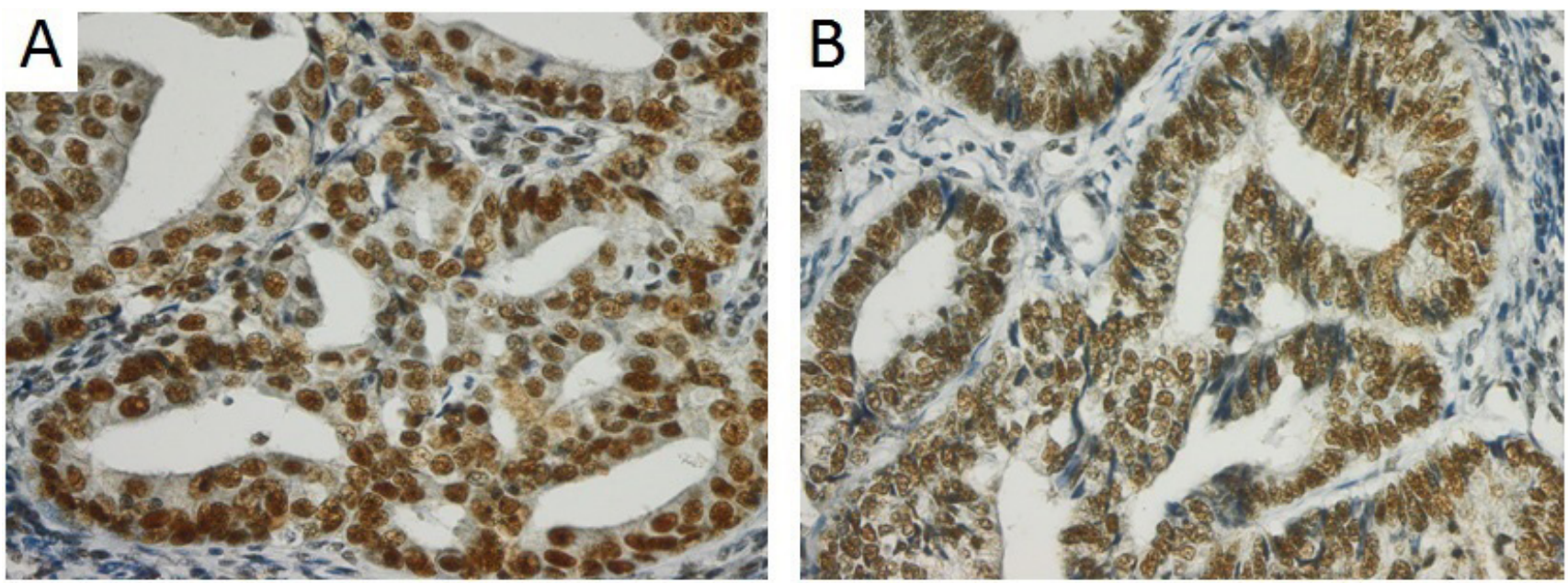

Fig. 4. A pronounced nuclear reaction with A) MLH1-specific antibody and B) MSH2-specific antibody in a section of endometrial adenocarcinoma. Magnification $\times 400$
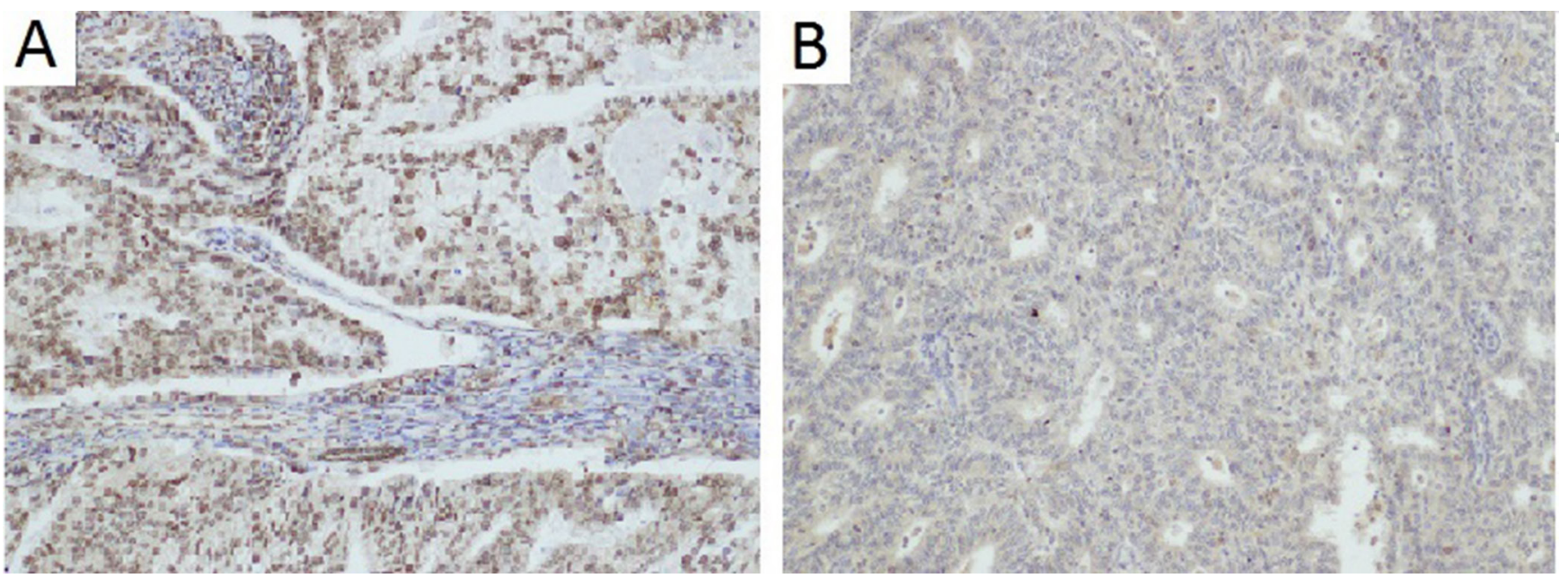

Fig. 5. Positive (A) and negative (B) nuclear reaction with BRCA1 antibody in a section of endometrial adenocarcinoma. Magnification $\times 10$ 


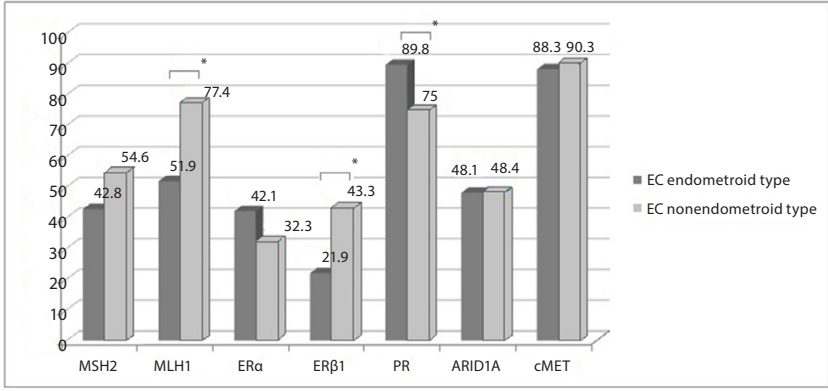

Fig. 6. The values reflect the proportions of endometrial cancer cases manifesting expression of a given protein in cells within the endometrioid and non-endometrioid types (immunohistochemical reaction of $+++/++) .{ }^{*} p<0.05$

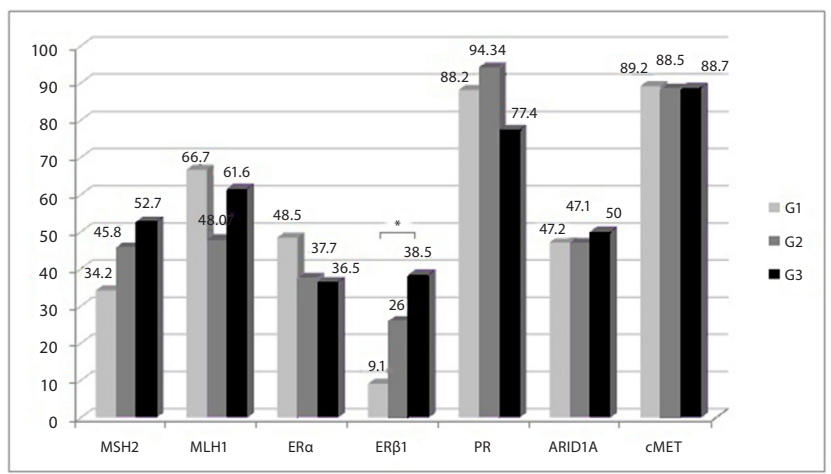

Fig. 7. The values reflect the proportion of endometrial cancer cases manifesting expression of a given protein in cells of a high, moderate or low histopathological grade (immunohistochemical reaction $+++/++$ ). ${ }^{*} p<0.05$

\section{International Federation of Gynecology and Obstetrics gynecologic cancer staging system}

For the analysis, patients with endometrial carcinoma were subdivided depending on the stage of clinical advancement of the disease into early stage of advancement (IA) and the late stage (IB-IV). Women manifesting stage IA showed a statistically significant higher expression of the ER $\alpha$ receptor $(\mathrm{p}=0.04)$. Patients with a more advanced disease manifested an augmented expression of the ER $\beta 1$ receptor $(\mathrm{p}=0.02)$ (Fig. 8). No differences were detected in the expression of MLH1, MSH2, PR, c-MET and ARID1A, which would depend on the stage of clinical advancement manifested by the disease.

\section{Mutation in BRCA1}

Patients with non-endometrioid cancer were subjected to an evaluation for the expression of BRCA1 protein in cancer tissue. Among 31 patients with type II EC, 16 proved to have negative expression of this protein (Table 2).

Among the patients with non-endometrioid type of EC lack of BRCA1, expression was correlated with reduced expression of $E R \alpha$ receptor $(p=0.02)$. No other differences in the expression of MLH1, MSH2, PR, ER $\beta 1, \mathrm{c}-\mathrm{MET}$ or ARID1A were detected among women with positive or negative BRCA1 staining (Fig. 9).

\section{Discussion}

Many endometrioid adenocarcinomas are thought to carry receptors for estrogens and progesterone. According to Reid-Nicholson et al., as many as $84 \%$ of endometrioid cancers (type I) manifest G1 and G2 maturity express ER receptors, as compared to ER expression in $9-54 \%$ of non-endometrioid (serous and clear-cell cancers). ${ }^{6}$ The expression of such receptors manifests a correlation exclusively with histological grading, but not with the clinical stage of the disease.

Estrogen receptors may be present in 2 isoforms: ER $\alpha$ and ER $\beta$, which exhibit distinct functions. ${ }^{25}$ Estrogen receptor $\beta$ is thought to function as a guardian of the endometrium; its disturbed expression has been described in most endometrial cancers. ${ }^{26}$ In our patients, the examination of ER $\beta 1$ expression demonstrated an increase in non-endometrioid cancer - type II EC (mainly serous carcinoma and clear-cell carcinoma) (Fig. 6) as compared to type I EC: 43.3 vs 21.9, respectively. The expression of ER $\beta 1$ increased parallel with histological grading: it was least pronounced in G1 - 9.1, higher in G2 - 26.0 and highest in G3 - 38.5 (Fig. 7). It also increased with the clinical advancement of the cancer: FIGO IA 11.8 vs FIGO IB-IV 31.7. In studies by Chakravarty et al. a decrease was also noted in the expression of ER $\beta$ in endometrioid EC cancers, but no differences were detected in the expression as related to grade. ${ }^{27}$ On the other hand, on the basis of our studies it may be accepted that an increased expression of ER $\beta 1$ in type II EC,

Table 2. BRCA1 protein expression status in studied patients with endometrial carcinoma type II

\begin{tabular}{|c|c|c|c|}
\hline $\begin{array}{c}\text { Histopathological } \\
\text { type }\end{array}$ & $\begin{array}{l}\text { FIGO } \\
\text { stage }\end{array}$ & $\begin{array}{c}\text { Number of } \\
\text { patients } \\
\text { with negative } \\
\text { BRCA1 expression } \\
\quad(n=16)\end{array}$ & $\begin{array}{c}\text { Number of } \\
\text { patients } \\
\text { with positive } \\
\text { BRCA1 expression }\end{array}$ \\
\hline \multirow{4}{*}{$\begin{array}{l}\text { Serous } \\
\text { adenocarcinoma }\end{array}$} & $\mid A$ & $\mathrm{n}=1$ & $n=3$ \\
\hline & IB & $n=1$ & $n=2$ \\
\hline & $\|$ & $n=2$ & $n=5$ \\
\hline & $\| I C 1$ & $n=3$ & $n=1$ \\
\hline \multirow{7}{*}{$\begin{array}{l}\text { Clear-cell } \\
\text { adenocarcinoma }\end{array}$} & $\mathrm{IA}$ & $n=1$ & $\mathrm{n}=0$ \\
\hline & $\mathrm{IB}$ & $n=1$ & $n=0$ \\
\hline & $\|$ & $n=2$ & $\mathrm{n}=0$ \\
\hline & $\| I \mid A$ & $n=1$ & $n=0$ \\
\hline & IIIC1 & $n=2$ & $n=1$ \\
\hline & IVA & $n=2$ & $n=0$ \\
\hline & IVB & $n=0$ & $n=1$ \\
\hline \multirow{2}{*}{$\begin{array}{l}\text { Mucinous } \\
\text { adenocarcinoma }\end{array}$} & $\|$ & $n=0$ & $n=1$ \\
\hline & IVB & $\mathrm{n}=0$ & $n=1$ \\
\hline
\end{tabular}




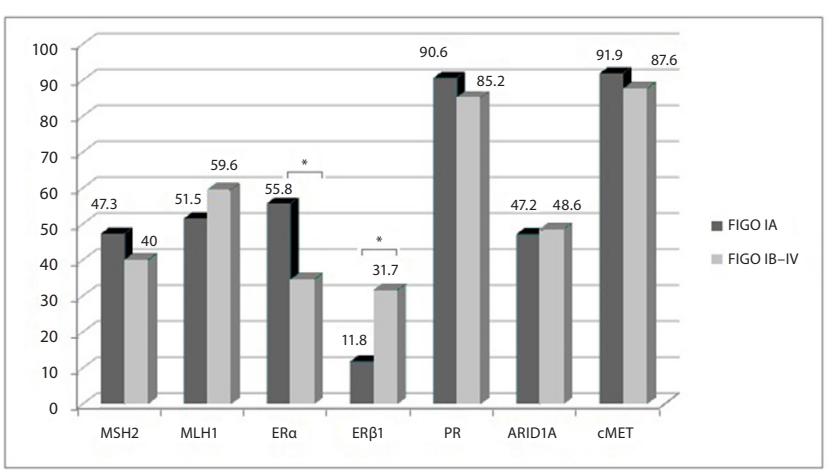

Fig. 8. The values reflect the proportion of endometrial cancer cases manifesting expression of a given protein in cells of early (IA) or more advanced degree (IB-IV) of clinical stage according to FIGO (immunohistochemical reaction $+++/++$ ). ${ }^{*} p<0.05$

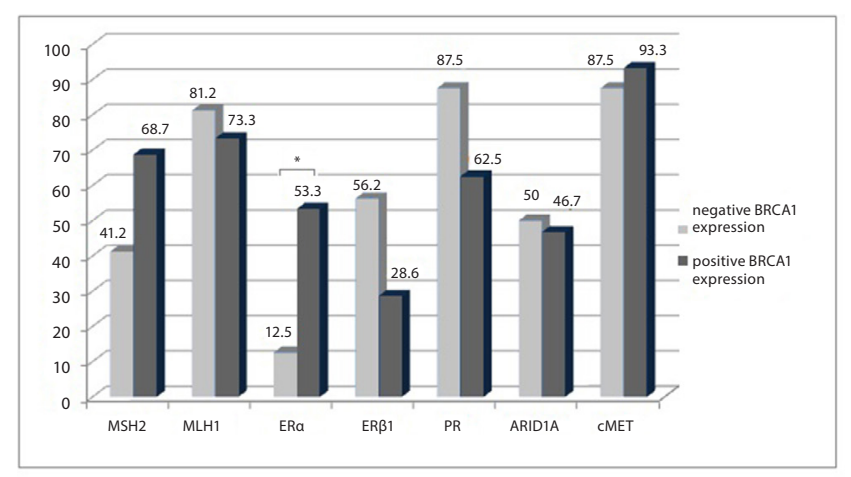

Fig. 9. The values reflect the proportion of endometrial cancer cases of non-endometrioid type manifesting expression of a given protein, as related to the expression of BRCA1 protein (immunohistochemical reaction $+++/++)$. ${ }^{*} p<0.05$

in the presence of poor differentiation (G3) and a higher stage of clinical advancement, was associated with poor prognosis.

Studies by Kreizman-Shefer et al. demonstrated that early endometrioid cancers preserve their expression of ER and PR, while poorly differentiated and clinically advanced cancers manifested an absence of 1 or both receptors. ${ }^{12}$ Similarly, in our studies the expression of ER $\alpha$ was higher in well or moderately differentiated cancers than in G3 cancers (48.5 vs 36.5 - Fig. 7), and it was also significantly higher in IA cancers according to FIGO (Fig. 8, FIGO 1A 55.8 vs FIGO IB-IV 34.6). We could not detect ER $\alpha$ expression in non-endometrioid type II cancers, although Sho et al. described it in $21.2 \%$ cases of USC, and this was linked to a poor prognosis. ${ }^{14}$

In studies by Togami et al., ER and PR expression in USC was associated with a good prognosis. ${ }^{13}$ In our studies the expression of the progesterone receptor PR was significantly more pronounced in type I endometrioid EC (89.8 in EV type I vs 75 in EC type II), which was consistent with the results of the study by Togami et al. ${ }^{13}$ However, we failed to identify differences in PR expression which would depend on histological grading $(G)$, as indicated in the studies by Reid-Nicholson et al. and those by Zhu et al.6,28
Since, as mentioned above, around 3-5\% of EC are linked to mutations in DNA-repair genes $(M M R)$, we estimated the expression of the 2 main relevant proteins, products of $\mathrm{MSH} 2$ and $\mathrm{MLH} 1$ genes, responsible for $85 \%$ cases of Lynch syndrome in all our patients. ${ }^{7,9,29}$ We detected a lower expression of MLH1 protein in endometrioid cancer (type I 51.9 vs type II 77.4), which may indicate that the $M L H 1$ gene mutation occurred more frequently in cases of type I EC. Berends et al. noted the loss of MLH1 expression among women with EC connected to Lynch syndrome. ${ }^{30}$

No abnormalities in the expression of ARID1A protein were revealed in our study. Other studies detected a loss of ARID1A expression in around 30\% of EEC cancers, in the progression of atypical hyperplasia to cancer as well as in the induction of many genes, including $M L H 1 .{ }^{21,31}$

Furthermore, the expression of the c-MET protein demonstrated no change in any of the parameters we examined, despite the evident association between c-MET and poor prognosis and metastasizing documented in other studies on EC. ${ }^{32-35}$

In 16 of our 31 patients (51.6\%) with a diagnosis of EC type II, immunohistochemical tests demonstrated an absent expression of BRCA1 protein, indicating a mutation in BRCA1. Such incidence was much higher than described by Bruchim et al. ${ }^{23}$ In studies by Raffi et al., $50.5 \%$ of USC patients were found to develop breast cancer (17.5\% before and 33\% following diagnosis of USC), which, according to the authors, suggested that the cases represented a proportion of $B R C A$ mutation syndrome. ${ }^{24}$ In our studies, the significantly reduced expression of the estrogen receptor $\alpha$ in this group of women might additionally indicate a relationship between some USC and BRCA mutation; it has been postulated that certain BRCA1 proteins inhibit ER $\alpha$ activity. ${ }^{36}$

\section{Conclusions}

An augmented expression of ER $\beta 1$ in EC was linked to type II EC. Higher expression of ER $\alpha$ in EC cancers was associated with a lower histopathological grade. A decreased expression of MLH1 protein was estimated in EC type I, which may indicate a mutation in $M L H 1$ gene in this type of cancer. Type II EC may be connected to BRCA1 mutation.

\section{References}

1. Globocan 2012 Estimated Cancer Incidence, Mortality and Prevalence Worldwide in 2012. http://globocan.iarc.fr/Pages/fact-sheetspopulation.asp. Accessed on January 17, 2015.

2. Ferlay J, Soerjomataram I, Ervik M, et al. Globocan 2012 v. 1.0. http:// globocan.iarc.fr. Accessed on January 16, 2015.

3. Bokhman JV. Two pathogenic types of endometrial carcinoma. Gynecol Oncol. 1983;15(1):10-17.

4. Setiawan VW, Yang HP, Pike MC, et al. Type I and II endometrial cancers: Have they different risk factors? J Clin Oncol. 2013;31(20):2607-2618.

5. Colombo N, Creutzberg C, Amant F, et al. ESMO-ESGO-ESTRO Consensus Conference on Endometrial Cancer: Diagnosis, treatment and follow-up. Int J Gynecol Cancer. 2016;25:1-24. 
6. Reid-Nicholson M, lyengar P, Hummer AJ, Linkov I, Asher M, Soslow RA. Immunophenotypic diversity of endometrial adenocarcinomas: Implications for differential diagnosis. Mod Pathol. 2006;19(8):1091-1100.

7. Colombo N, Preti E, Landoni F, Carinelli S, Colombo A. Endometrial cancer: ESMO clinical practice guidelines for diagnosis, treatment and follow-up. Ann Oncol. 2013;24(Suppl 6):vi33-vi38.

8. Cossio SL, Koehler-Santos P, Pessini SA, et al. Clinical and histomolecular endometrial tumor characterization of patients at-risk for Lynch syndrome in south of Brazil. Fam Cancer. 2010;9(2):131-139.

9. Huang M, Djordjevic B, Yates MS, et al. Molecular pathogenesis of endometrial cancers in patients with Lynch syndrome. Cancer. 2013;119(16):3027-3033.

10. Fader AN, Santin AD, Gehrig PA. Early stage uterine serous carcinoma: Management updates and genomic advances. Gynecol Oncol. 2013;129(1):244-250.

11. Attias-Geva Z, Bentov I, Kidron D, et al. p53 regulates insulin-like growth factor-I receptor gene expression in uterine serous carcinoma and predicts responsiveness to an insulin-like growth factor-I receptordirected targeted therapy. Eur J Cancer. 2012:48(10):1570-1580.

12. Kreizman-Shefer H, Pricop J, Goldman S, Elmalah I, Shalev E. Distribution of estrogen and progesterone receptors isoforms in endometrial cancer. Diagn Pathol. 2014;9:77.

13. Togami S, Sasajima Y, Oi T, et al. Clinicopathological and prognostic impact of human epidermal growth factor receptor type 2 (HER2) and hormone receptor expression in uterine papillary serous carcinoma. Cancer Sci. 2012;103(5):926-932.

14. Sho T, Hachisuga T, Nguyen TT, et al. Expression of estrogen receptor- $a$ as a prognostic factor in patients with uterine serous carcinoma. Int J Gynecol Cancer. 2014;24(1):102-106.

15. Park JY, Nam JH, Kim YT, et al. Poor prognosis of uterine serous carcinoma compared with grade 3 endometrioid carcinoma in early stage patients. Virchows Arch. 2013;462(3):289-296.

16. Sagae S, Susumu N, Viswanathan AN, Aoki D, Backes FJ, Provencher DM. Gynecologic Cancer InterGroup (GCIG) consensus review for uterine serous carcinoma. Int J Gynecol Cancer. 2014;24(9 Suppl 3):S83-S89.

17. Hampel H, Frankel W, Panescu J, et al. Screening for Lynch syndrome (hereditary nonpolyposis colorectal cancer) among endometrial cancer patients. Cancer Res. 2006;66(15):7810-7817.

18. Bischoff J, Ignatov A, Semczuk A, et al. $h M L H 1$ promoter hypermethylation and MSI status in human endometrial carcinomas with and without metastases. Clin Exp Metastasis. 2012;29(8):889-900.

19. Brinton LA, Felix AS, McMeekin DS, et al. Etiologic heterogeneity in endometrial cancer: Evidence from a Gynecologic Oncology Group trial. Gynecol Oncol. 2013;129(2):277-284.

20. Hayes MP, Ellenson LH. Molecular alterations in uterine serous carcinoma. Gynecol Oncol. 2010;116(2):286-289.

21. Takeda T, Banno K, Okawa R, et al. ARID1A gene mutation in ovarian and endometrial cancers (Review). Oncol Rep. 2015;35(2):607-613.

22. Bishop EA, Lengyel ER, Yamada SD, Montag A, Temkin SM. The expression of hepatocyte growth factor (HGF) and c-MET in uterine serous carcinoma. Gynecol Oncol. 2011;121(1):218-223.

23. Bruchim I, Amichay $\mathrm{K}$, Kidron $\mathrm{D}$, et al. BRCA1/2 germline mutations in Jewish patients with uterine serous carcinoma. Int J Gynecol Cancer. 2010;20(7):1148-1153.

24. Rafii S, Dawson P, Williams S, Pascoe JS, Nevin JE, Sundar S. Is uterine serous carcinoma a part of hereditary breast cancer syndrome? J Clin Oncol. 2013;31 (suppl; abstr 5587). doi: 10.1200/jco.2013.31.15_suppl.5587

25. Zhao C, Dahlman-Wright K, Gustafsson JA. Estrogen receptor beta: An overview and update. Nucl Recept Signal. 2008;6:e003.

26. Hapangama DK, Kamal AM, Bulmer JN. Estrogen receptor $\beta$ : The guardian of the endometrium. Hum Reprod Update. 2015;21(2):174-193.

27. Chakravarty D, Srinivasan R, Ghosh S, Gopalan S, Rajwanshi A, Majumdar S. Estrogen receptor beta1 and the beta2/betacx isoforms in non-neoplastic endometrium and in endometrioid carcinoma. Int J Gynecol Cancer. 2007;17(4):905-913.

28. Zhu C, Luo J, Shi H, Xie X, Ding Z. Expression of tubulin, p53, ki67, receptors for estrogen, and progesterone in endometrial cancer. Eur J Gynaecol Oncol. 2009;30(5):514-517.

29. Lindor NM. Lynch syndrome 101 (years, that is). Am Soc Clin Oncol Educ Book. 2014:27-32. doi: 10.14694/EdBook_AM.2014.34.27

30. Berends MJW, Hollema $\mathrm{H}, \mathrm{Wu} Y$, et al. MLH1 and MSH2 protein expression as a pre-screening marker in hereditary and non-hereditary endometrial hyperplasia and cancer. Int J Cancer. 2001;92:398-403.
31. Bosse T, ter Haar NT, Seeber LM, v Diest PJ, Hes J, Vasen HFA. Loss of ARID1A expression and its relationship with PI3K-Akt pathway alterations, TP53 and microsatellite instability in endometrial cancer. Mod Pathol. 2013;26:1525-1535.

32. Li M, Xin X, Wu T, Hua T, Wang H, Wang H. Stromal cells of endometrial carcinoma promotes proliferation of epithelial cells through the HGF/ c-MET/Akt signaling pathway. Tumour Biol. 2015;36(8):6239-6248.

33. Zhuang XP, Jin WW, Teng XD, Yuan ZZ, Lin QQ, Xu ST. c-MET and RON expression levels in endometrial adenocarcinoma tissue and their relationship with prognosis. Eur J Gynaecol Oncol. 2015;36(3):255-259.

34. Li M, Xin X, Wu T, Hua T, Wang H. HGF and c-MET in pathogenesis of endometrial carcinoma. Front Biosci. 2015;20:635-643.

35. Felix AS, Edwards RP, Stone RA, et al. Associations between hepatocyte growth factor, c-MET, and basic fibroblast growth factor and survival in endometrial cancer patients. Br J Cancer. 2012;106(12):2004-2009.

36. Fan $\mathrm{S}, \mathrm{Ma} Y \mathrm{X}$, Wang $\mathrm{C}$, et al. Role of direct interaction in $B R C A 1$ inhibition of estrogen receptor activity. Oncogene. 2001;20(1):77-87. 